\title{
SEMBLANZA
}




\section{JAIME JARAMILLO URIBE Y EL IMPACTO DE SU OBRA*}

\section{Jorge Orlando Melo*}

Me complace mucho en acompañar hoy al profesor Jaime Jaramillo Uribe en esta reunión en la que se da el más alto reconocimiento que existe en Colombia de mis contemporáneos dedicados a la historia, a las ciencias sociales o de la cultura, en deuda con ese trabajo paciente y sobrio del profesor Jaramillo. Tuve la fortuna de encontrarlo en la Universidad Nacional, a comienzos de la década de 1960, y no voy a cometer la impertinencia de referirme a todo lo que pude aprender al tenerlo como profesor y, luego, como colega y amigo. Quiero más bien señalar aquellos elementos y rasgos de su trabajo como historiador y como pensador que más han contribuido a darle un matiz especial a la actividad de investigación histórica y a la reflexión social en Colombia.

Si uno trata, con algo de audacia y de simplificación de presentar someramente el ambiente cultural de Colombia a finales de la década de 1950, debe subrayar, por una parte, la persistencia obstinada de formas de pensamiento y de hábitos culturales muy ajenos a las exigencias de rigor de las disciplinas sociales modernas. En filosofía, sociología, historia, la enseñanza y la reflexión se limitan en muchas instituciones al aprendizaje de simplificadas versiones del pensamiento europeo, a veces teñidas de un abigarrado enciclopedismo, pero sin un esfuerzo de pensamiento propio. Estas formas de pensamiento poco se distanciaban de argumentaciones apologéticas, la mayoría orientadas en un sentido tradicionalista, escolástico y católico, pero a cuyos rasgos fundamentales no eran ajenas las vertientes más heterodoxas o radicales. Para católicos liberales, radicales o marxistas, la historia y la ciencia social eran, sobre todo, herramientas en un debate político bastante simplificado, que no respetaba las exigencias analíticas propias de cada disciplina, ni adoptaba la actitud de búsqueda de conocimiento que resulta esencial para desarrollar la actividad investigativa y reflexiva. Nuestras ciencias sociales eran deductivas, y más que basadas en la lectura de los trazos de la realidad de nuestra historia estaban al servicio de la polémica política.

Buena parte de esto era el resultado del renacer de un espíritu inquisitorial e intransigente, que renovaba lazos con los elementos más restrictivos del espíritu que animó lo que podría llamarse el espíritu cultural de la regeneración. Durante los años treinta y cuarenta, el país vivió una reiterada confrontación entre quienes querían imponer una cultura monolítica, marcada por rasgos de catolicismo integrista y un rechazo sistemático a la ciencia, y quienes querían abrir el país a la cultura contemporánea y disminuir la distancia intelectual que separaba al país de los centros científicos y culturales de la época. En varias instituciones y otros lugares de la cultura nacional se habían conformado pequeños grupos de intelectuales que estaban transformando, callada y tranquilamente, la actividad universitaria. Una contribución excepcional a la constitución de estas formas de pensamiento transformadoras podría atribuirse a la Escuela Normal Superior, en la cual se formó inicialmente Jaime Jaramillo Uribe, como lo hicieron Luís Duque Gómez, Virginia Gutiérrez de Pineda, Roberto Pineda Duque y otros científicos sociales. La influencia del profesor José Francisco Socarrás en su orientación inicial, en su preocupación por los problemas colombianos, en la visión de una ciencia social atenta al país pero rigurosa e independiente, ha sido reconocida con generosidad por el profesor Jaramillo.

Si hemos de pensar en el ambiente político debemos tener en cuenta la adopción de un liberalismo de izquierda, con algunos tintes marxistas, por parte de importantes

\footnotetext{
** Historiador, Director de la Biblioteca Luis Ángel Arango. 
sectores de académicos, que trataron de preguntarse por los caracteres propios de nuestra sociedad, con un poco más de atención a esos aspectos de la estructura social que en lenguaje marxista se definían como materiales: la economía, las formas de organización social, los conflictos entre clases. Aun en obras que no alcanzaron el rigor y la seriedad de los trabajos posteriores de Jaramillo Uribe o de Luis Ospina Vásquez, como las obras de Antonio García, de Guillermo Hernández Rodríguez o de Luís Eduardo Nieto Arteta, puede advertirse el afán de utilizar un aparato conceptual ambicioso y, dados los antecedentes del país, moderno, para superar la simplificación ideológica en el conocimiento de la realidad. Procesos similares de apertura cultural se advertían en el mundo de la literatura, en el que los herederos de Panida o Los Nuevos, reunidos alrededor de publicaciones como la Revista de Indias, sacudían las convenciones más estrechas de la retórica tradicional. O en el mundo del arte, sacudido por la pintura de Pedro Nel Gómez o Débora Arango, para mencionar sólo algunas de aquellas personas que de alguna manera personificaron el enfrentamiento cultural y fueron víctimas del esfuerzo de represión de lo nuevo, que cubrió sus cuadros, los borró o los condenó al silencio.

En esos años ofrecía, además, Latinoamérica, cosa que tienden a olvidar quienes ven en el boom literario la causa de la constitución de un público regional más o menos unificado, un importante flujo de influencias horizontales, apoyados en la actividad editorial de México, Chile y Argentina. Editoriales como el Fondo de Cultura Económica de México, y Losada, Argos y Nova de Buenos Aires, para mencionar sólo unos pocos ejemplos, permitieron a los intelectuales más serios un acceso temprano a obras como las de Dilthey, Weber, Simmel o Scheler pero, además, puso en contacto a historiadores y pensadores sociales como Jorge Luis Romero. Sergio Buarque da Hollanda, Silvio Zavala, Leopoldo Zea o Gilberto Freyre, de todos los cuales fue atento lector el profesor Jaramillo.

Sin embargo, en el contexto de polarización ideológica y de cruzada que amplios sectores del país trataron de imponer desde mediados de los años treinta, para enfrentarse a las transformaciones que se realizaban en el terreno de la vida política, de la sociedad, de la educación y de la cultura, el trabajo serio del núcleo científico del cual fue ejemplo la Escuela Normal quedó identificado, en la visión de los sectores más tradicionalistas, con el proyecto integral de la república liberal, y por ello, en la retórica terrorista de la época, con el intento del bolchevismo, del protestantismo, del modernismo, por acabar con los elementos más valiosos de nuestra cultura y nuestra nacionalidad. La asociación era, en parte, justificada: existían evidentes afinidades entre los esfuerzos de creación científica, de análisis riguroso de la sociedad colombiana, de apertura al mundo, y el espíritu del cambio político impulsado por la república liberal. Pero era en parte arbitraria, en cuanto los elementos más estridentes del proyecto liberal estaban en el fondo más cerca de la retórica tradicional colombiana, de la confrontación política intransigente y poco sólida, que del trabajo intelectual de estos pioneros. Pero la estrategia intimidadora tuvo finalmente éxito, y el país debió volver a frenar en seco y a presenciar la destrucción consciente e irresponsable de los mejores esfuerzos educativos y culturales del país a finales de los cuarenta y comienzos de la década del cincuenta.

Jaramillo estuvo fuera de Colombia durante buena parte de los años inmediatos de la postguerra. Sería extraordinario poder contar algún día con una memoria intelectual de su proceso de formación, en el que podamos advertir la forma como la experiencia europea contribuyó a la formación de su visión. La Francia de 1946 a 1948, en la que maduraban y se imponían filósofos como Sartre era también la nación en la que, un poco más calladamente, construía su hegemonía como guía del trabajo histórico la revista que había 
dirigido Marc Bloch y estaba ahora bajo la orientación de Lucien Febvre y Fernand Braudel, los Annales. Volvió a estar en Europa, esta vez en Alemania, en 1954, cuando tenía bastante avanzado su primer trabajo de envergadura, el estudio sobre el pensamiento colombiano del siglo XIX: la historia como ciencia de la cultura, ejemplificada magistralmente por Ernst Cassirer, estuvo en la base de este trabajo que sigue teniendo hoy todo el valor y la novedad de entonces. Todos estos autores, todas estas lecturas contribuyeron a que su obra no tuviera el menor tinte de parroquialismo, a que la conciencia de lo propio estuviera siempre inscrita en una apertura a los más exigentes conceptos del pensamiento moderno.

Estas semillas de pensamiento moderno no se perdieron ni siquiera a causa del endurecimiento y marasmo que alcanzó a producirse por el esfuerzo superficial del Estado de volver a construir una cierta unidad ideológica muy tradicionalista e hispanista del país. La Universidad estaba creando las primeras formas de trabajo académico no profesionalista, filosófico y reflexivo. Pienso en el Instituto de Filosofía de la Universidad Nacional, en el que trabajaban a comienzos de los años cincuenta Danilo Cruz Vélez, Cayetano Betancur y Rafael Carrillo, o en la Escuela de Economía, de la que hicieron parte Antonio García y Luis Ospina Vásquez, y uno de cuyos desprendimientos fue el departamento de Sociología, encabezado por Orlando Fals Borda. En esa universidad de finales de los cincuenta alcanzó un primer desarrollo una nueva forma de ciencia social del país. Creo, personalmente, que ésta es una de las transformaciones culturales más importantes que se ha dado en la historia del país, y que estuvo acompañada por una afirmación paralela de modernización en otras áreas de la vida cultural. Aunque no pueda argumentarlo, ni mostrar lo complejo y matizado del proceso, me parece que la ruptura literaria representada por la obra de Gabriel García Márquez, o el desarrollo de pinturas como la de Obregón y la de Botero, que quizás encontraron su canal modernizador, con una estridencia algo mayor, co algo más de teatralidad y de vocación voluntarista de modernidad en Mito, hacen parte del mismo proceso que sacudió la tradición cultural del país, de ese mismo cambio del que podría decirse, parodiando las palabras de Virginia Woolf sobre la Inglaterra de 1910, se di en algún momento de cierto mes de 1958.

Los herederos de esto fuimos, en buena parte, los que llegamos la universidad en la década de 1960. En historia, hicimos parte d reducido grupo de personas que tomamos los cursos sobre historia de Colombia o sobre filosofía de la historia, Germán Colmenares, Jorge Palacios, Hermes Tovar, Margarita González, Víctor Álvarez unos cuantos más: de una u otra manera, con mayor o menor calidad, alrededor del trabajo de los alumnos de Jaramillo se consolidó la disciplina universitaria histórica de los últimos veinte años. Cuando en 1977 se comenzó a realizar el proyecto de escritura del Manual de Historia de Colcultura, ya existía una nueva visión de la historia nacional y un grupo capaz de darle un mínimo de coherencia: fu Jaime Jaramillo Uribe, el que, dejando la más amplía libertad a los colaboradores, orientó un trabajo que, visto un cuarto de siglo después, sigue siendo ejemplar. También en esos años se publicó la recopilación de trabajos históricos hecha por Darío Jaramillo en la que dio, con talento de publicista, el nombre de "Nueva Historia" a los enfoques que comenzaban a imponerse. A pesar de que, como es evidente, la llamada nueva historia no constituyó una escuela, ni sus miembros tuvieron una perspectiva metodológica única, algo los unía, y las que eran sus virtudes debían mucho a la enseñanza dc Jaramillo. Para el público, la nueva historia fue en buena parte su creación, reforzada por figuras como Luis Ospina Vásquez y Juan Friede, y a la que se vincularon, fuera de los estudiantes directos dc Jaramillo Uribe, investigadores provenientes de otras disciplinas y otras formaciones, como Alvaro Tirado, Jesús Antonio Bejarano. Miguel Urrutia, Salomón Kalmanovitz, Marco Palacios y José Antonio Ocampo. 
Trazar el complejo laberinto de influencias, choques, de la historia reciente no es pertinente. Simplemente creo que vale la pena recordar que Jaramillo Uribe creó en 1962 el Anuario Colombiano de Historio Social y de la Cultura, y lo dirigió durante ocho años, en lo que se convirtió en un eje de la formación de los historiadores locales y de la divulgación de su trabajo. No era una revista que buscara lectores, y su carácter casi ladrilludo, su hirsuta renuencia a atraer al lector eran muy coherentes con la estrategia pedagógica de Jaramillo, que nunca fue paternalista, complaciente o seductora: había que formar a la gente en la disciplina de la lectura del documento, en la invitación a trabajo de archivo, en el esfuerzo de la interpretación, en el rigor de $\mathrm{h}$ expresión. El historiador necesitaba una sólida formación filosófica y de ciencias sociales, y cierta calidad estética, que sólo podía adquirirse en la familiaridad con los grandes clásicos de la literatura, era también esencial. Tanto como el rigor investigativo, me parece que ha exigido siempre Jaramillo la sobriedad en la exposición, la buena escritura, ajena a todo desborde retórico. Todas estas eran formas d rechazo a la tendencia a la especulación sin bases, encubierta usualmente en una retórica literaria. Pero también en su docencia era central el rechazo a todo dogmatismo, a toda simplificación basada en $k$ aplicación de fórmulas más o menos fáciles. Aunque respetaba los aportes y la inteligencia de Nieto Arteta, subraya siempre la precariedad de sus simplificaciones, la ingenuidad de pretender decir desde el presente lo que debían haber hecho los hombres del siglo XIX, el anacronismo de muchas de sus críticas al librecambismo. En un ambiente dc beatería reverencial como el que podían tener los jóvenes de esa década de radicalismo político y de descubrimiento de las virtudes del marxismo que fueron los sesenta, el escepticismo de Jaramillo frente a los grandes sistemas, y su actitud hacia el marxismo influyeron bastante, en mi opinión, para que muy pocos de sus estudiantes asumieran el marxismo, que estaba en el ambiente, en la forma dogmática e integral como se asumió en otros medios, colombianos y latinoamericanos. Los historiadores colombianos de las últimas décadas fueron, entre los que se formaron en las universidades en época de la revolución cubana, los que menos se dejaron seducir por las modas intelectuales del marxismo parisino: mientras Althusser era repetido por muchos, los historiadores formados bajo la influencia de Jaramillo preferíamos que nos acusaran de empiristas, y buscábamos en algunos autores europeos como Pierre Vilar o Edward Thompson ejemplos que de que se podía ser historiador moderno y riguroso aprendiendo de Marx pero sin convertir la historia otra vez en pura herramienta del debate político.

He hablado probablemente más de nosotros que de Jaramillo. Me excuso hoy de discutir las importantes contribuciones que su obra ha hecho al conocimiento del pasado. No entro en detalles de cómo cambió el mapa de lo que era digno de investigación, al abrir el inmenso territorio de la historia de las ideas y, sobre todo, el de la historia social, en el que pocos trabajos han superado el interés, la complejidad y la agudeza de un articulo como el que analizaba las relaciones entre esclavos y señores. Subrayo hoy más bien lo que hizo Jaramillo, como docente, como promotor del trabajo histórico moderno, para cambiar el paisaje cultural del país. Y esto, porque creo que, a pesar del tono modesto de sus contribuciones, de la ausencia de toda autopromoción, la obra callada, la acción tranquila de Jaramillo Uribe nos ha transformado. Y eso no es fácil de decirlo ni de demostrarlo: ni el PIB ni el índice de Gini son hoy probablemente distintos a lo que habrían sido si Jaime hubiera dedicado sus esfuerzos a algo distinto al mundo del pensamiento y la investigación. La gran mayoría de los colombianos nunca han oído, ni oirán hablar de él. Pero si en nuestro país se sigue respetando a los científicos sociales que pueden escribir bien, que tratan de argumentar con rigor, que no ceden a las argumentaciones especiosas y sofistas de quienes no tienen una actitud verdaderamente investigativa, así estos sean temas que aparentemente no conciernen sino a una élite de intelectuales, esto se debe en buena parte a personas como Jaramillo. Y cuando en un 
remoto pueblo colombiano los estudiantes de historia del colegio local, en vez de tener que sufrir el aprendizaje mecánico de una serie de inconexos incidentes, tropiezan con un texto que trata de que adquieran cierta conciencia de las grandes corrientes de cambio de nuestra sociedad, que hagan de la historia la historia de su propia vida y no un repertorio exótico de acciones heroicas, que se pregunten por nuestros conflictos sociales, por la diversidad de nuestras tradiciones culturales, por tantas que hoy parecen ser naturales 0 estar de moda, pero parecían remotas hace 25 años, esa pequeña suerte, que hoy no es tan insólita, se debe en buena parte a personas como Jaime Jaramillo Uribe, y por ello todos debemos estar muy agradecidos. 